\title{
Anti-Aging Liposomal formulation: A Mini Review
}

\author{
Marafi Ansam¹, Ruba Bnyan ${ }^{1}$, Sakib Yousaf ${ }^{2}$ and Iftikhar Khan ${ }^{1 *}$ \\ ${ }^{1}$ School of Pharmacy and Bio molecular Sciences, Liverpool John Moores University, UK \\ ${ }^{2}$ School of Pharmacy and Biomedical Sciences, University of Central Lancashire, UK
}

Submission: December 21, 2017; Published: January 08, 2018

*Corresponding author: Iftikhar Khan, School of Pharmacy and Bio molecular Sciences, John Moores University, UK, Tel: (+44) 1512312736

Email: I.Khan@ljmu.ac.uk, iftikharkhans@yahoo.com

Abstract

Due to very intensive and technological industrial development, different preparation techniques are being introduced to the pharmaceutical/ cosmeceutical industry. Lipid-based formulation cover most of the formulations based on cosmetics products. They are primarily used in antiaging products. Liposomes used as a carrier for anti-aging and cosmeceutical formulations in order to exhibit better absorption properties by the skin than the standard cosmeceutical products. The use of liposomes in Cosmeceutical preparations is a promising technique for the formulation of more effective anti-aging products with less side effects, improved stability and a targeted delivery of the active component.

Keywords: Liposome; Anti-aging; Nanotechnology; Cosmeceutical, Pharmaceutical

\section{Introduction}

\section{Anti-aging}

Increasing the expectancy of median life as well as improving the quality of life and preventing the consequences of aging are receiving a great attention in research at the present time [1]. Everlasting youth have always interested humankind, now the goal of youth have changed to increasing the duration of healthy lifestyle of an individual rather than increasing the life span only [2]. Cosmeceutical formulations, researchers and pharmacists are paying extra attention to the aging consequences in the skin, trying to find cost effective solutions for this difficult problem. The society and scientists are in a continuous battle with the aging process and its concerns; skin aging especially as this is visually perceptible. People try to compete with nature by using topical products as well as some indigenous preparations to slow down the process. Estimates show that around 2 billion dollars were spent on anti-aging products in the United States in 2000 [3]. Ancient Egyptians, Chinese, Indians and Greeks were continuously searching for everlasting youth secrets, and were constantly looking for methods and remedies to compete with the ageing process [2]. An over-all understanding of the skin aging process will yield a better anti-aging products development. In general, aging of all tissues including the skin occurs due to intrinsic (i.e. genetic) as well as the extrinsic factors such as smoking, free radicals and life style.

Some people used to apply herbal products as an anti-aging products millennia ago. This is because there was some thought that the anti-aging natural remedies improved the skin's texture and reduced the appearance of wrinkles, as well as reducing existing fine lines without knowing the specific mechanism of action of these natural products. In ancient Egypt, Cleopatra used to add donkey's milk to her legendary milk bath but this is seldom done anymore [4]. Cosmeceutical science in our time focuses on the raw materials and formulations of cosmeceutical products and their effect on the human body. Anti-aging products and their formulation techniques including herbal products have become a huge part of this modern science [5]. Turmeric, or so called the Indian solid gold, has been used since 1900 BC (the time of Ayurveda) not just in food, but also in skin conditions due to its anti-oxidant as well as the anti-inflammatory effects [6].

\section{Nanotechnology}

The Global demand of anti-aging and other cosmeceutical products in the present time led to research and discovering of new techniques for formulating and improving the existing formulas of the anti-aging and cosmeceutical products [7]. Nanotechnology can be used in cosmeceutical products formulations, where nano-molecules are entities with particle size between approximately $1 \mathrm{nM}$ to $100 \mathrm{nM}$ (i.e. one billionth of a meter), and this in turn will change the properties of the molecules and their reactivity [8]. Creams, shampoos, conditioners, shaving foams and gels, lotions and anti-aging products are some examples of the nano-particles formulated 
products [9]. Liposome cosmeceutical formulations are a very good example of nano-particles technology, where the change of the properties of the molecules are size-dependent.

The cosmeceutical formulations that contain nanoparticles tends to have better absorption by the skin, cause less irritation to the skin and hence less undesirable effect. They may also sustain the release of an active ingredients and therefore an enhanced effect of the product can be achieved. It is very important to emphasize that the encapsulation process will also protect the active ingredient from oxygen, light, moisture and other recipients in the formulation, which in turn makes the formulation more stable when prepared using the appropriate method. This stability will have a great impact on the permeation rate into the skin and result in a steady and continuous permeability. Moreover, the encapsulation of the active ingredients will lead to more convenient delivery to the targeted site than ordinary formulations [9].

\section{Liposomes}

Liposomes are sphere-shape vesicle and mainly consists of phosphor lipid bi layer encircling a polar core. The function of the liposomes strongly depends on their properties and classification. They are categorised based on their size, number of phosphor lipid bi layers or the phosphor lipid charge $[10,11]$. Phospholipids may be a derived from either animal or botanical origin; soybean is an example of plant-derived base material while egg yolk with relatively large content of phosphatidylcholine is an example of animal derived base material. Regardless of the cost effectiveness of soybean, their storage stability is not that great. The instability of soybean and other natural phospholipids is generally due to the unsaturated fatty acid group [12]. The very basic unit of the liposome consist of two key components, a hydrophilic head and a hydrophobic tail linked by a phosphate group and glycerol. This basic unit creates the phosphor lipid bi layer (double layer). The hydrophilic heads form the polar part (i.e. central core), where hydrophilic pharmaceutical active ingredients are encapsulated; while the hydrophobic part, consisting of two fatty acid chains, can incorporate hydrophobic pharmaceutical ingredients [13-16]. The encapsulation process in the pharmaceutical industry is utilised in fragrances to yield a sustained release, to protect volatile components present in the formulation as well as providing a delayed release in some products [17-19].

The choice of phospholipid as a basic unit in cosmeceutical products in liposomal formulation is crucial especially if the phospholipid is of a natural origin. The liposome should be able to encapsulate a hydrophilic material and hold lipophilic material or slightly insoluble materials in their surface membrane [11]. While unilamellar vesicles are the best choice when using liposomes for pharmaceutical topical products, multi lamellar vesicles are the most suitable form when using liposomes for the cosmeceutical products formulation. This is due to the release of the entire active ingredient when the membrane breaks in unilamellar liposome. Contrastingly, multi lamellar liposomes have a better structural stability and hence they are the most suitable option for the use in the cosmeceutical topical preparations [11].

\section{Conclusion}

Pharmaceutical/cosmaceutical industry, researchers and pharmacists have raised concern about the most effective method to formulate anti-aging products using best ingredients. Penetration of the active ingredient by the skin in different formulations is another major challenge. This is due to their hydrophilicity and the presence of long ester chains in ascorbic palmitate and the presence of different forms of active ingredients. The use of a lipid-based formulation system such as liposomes should yield a better impact on the stability, as well as the release of the active ingredient. It should also reduce the undesirable effects that are caused by the classic ascorbic acid formulated anti-aging cosmeceutical products, that is because of the better and targeted site penetration of the active ingredient to the skin.

\section{References}

1. Makrantonaki E, Zouboulis CC (2007) The skin as a mirror of the aging process in the human organism. State of the art and results of the aging research in the German National Genome Research Network 2 (NGFN2) 42(9): 879-886.

2. Ho YS, So KF, Chang RC (2010) Anti-aging herbal medicine. How and why can they be used in aging-associated neurodegenerative diseases? Ageing Research Reviews 9(3): 354-362.

3. Thomas J Regan, Dixon Tatiana K, Bhattacharyya Tapan K (2013) Effects of Topicals on the Aging Skin Process 21(1): 55-60.

4. Cunsolo V, Muccilli V, Fasoli E, Saletti R, Righetti PG et al. (2011) Poppea's bath liquor: The secret proteome of she donkey's milk. Journal of Proteomics 74(10): 2083-2099.

5. Wang KH, Lin RD, Hsu FL, Huang YH, Chang HC et al. (2006) Cosmetic applications of selected traditional Chinese herbal medicines. Journal of Ethnopharmacology 106(3): 353-359.

6. Aggarwal BB, Sundaram C, Malani N, Ichikawa H (2007) Curcumin: the Indian solid gold, Adv Exp Med Biol 595: 1-75.

7. FS Brandt, A Cazzaniga, M Hann (2011) Cosmeceuticals: current trends and market analysis 30(3): 141-143.

8. Auffan M, Rose J, Bottero JY, Gregory V, Lowry Jean Pieree Jolivet, et al. (2009) Towards a definition of inorganic nanoparticles from an environmental, health and safety perspective. Nature Nanotechnology 4: 634-641.

9. Nafisi S, Maibach HI (2017) Nanotechnology in Cosmetics in Cosmetic Science and Technology, Amsterdam: Elsevier 337-369.

10. Vemuri S, Rhodes CT (1995) Preparation and characterization of liposomes as therapeutic delivery systems: a review, Pharmaceutica Acta Helvetiae 70(2): 95-111.

11. Patil YP, Jadhav S (2014) Novel methods for liposome preparation, Chemistry and Physics of Lipids 177: 8-18.

12. Himeno T, Konno Y, Naito N (2017) Liposomes for Cosmetics' in Cosmetic Science and Technology, Amsterdam: Elsevier 539-549. 
13. Khan I, Elhissi A, Shah M, Alhnan MA, Waqar A (2013) Liposomebased carrier systems and devices used for pulmonary drug delivery. In: DAVIM JP (ed.) Biomaterial and medical tribology research and development pp. 395-443.

14. Khan I, Yousaf S, Subramanian S, Korale O, Alhnan MA, et al. (2015) Proliposome powders prepared using a slurry method for the generation of beclometasone dipropionate liposomes. International Journal of Pharmaceutics 496(2): 342-350

15. Subramanian S, Khan I, Korale O, Alhnan MA, Ahmed W, et al. (2016) A simple approach to predict the stability of phosphor lipid vesicles to nebulization without performing aerosolization studies. International Journal of Pharmaceutics 502(1-2): 18-27.

16. Khan I, Yousaf S, Subramanian S, Alhnan M A, Ahmed W, et al. (2017) Proliposome Powders for the Generation of Liposomes: the Influence of Carbohydrate Carrier and Separation Conditions on Crystallinity and Entrapment of a Model Antiasthma Steroid. AAPS PharmSciTech p.1-13.

17. Brannon Peppas L (1993) Controlled Release in the Food and Cosmetics Industries in Polymeric.Delivery SystemsAmerican Chemical Society $\mathrm{p}$ 42-52.

18. Kirby C, Gregoriadis G (1984) Dehydration Rehydration Vesicles: A Simple Method for High Yield Drug Entrapment in Liposomes 2: 979 984.

19. Mozafari MR (2005) Liposomes: An Overview of Manufacturing Techniques. Cellular \& Molecular Biology 10(4): 711-719.

\section{Your next submission with Juniper Publishers will reach you the below assets}

- Quality Editorial service

- Swift Peer Review

- Reprints availability

- E-prints Service

- Manuscript Podcast for convenient understanding

- Global attainment for your research

- Manuscript accessibility in different formats

( Pdf, E-pub, Full Text, Audio)

- Unceasing customer service

Track the below URL for one-step submission https://juniperpublishers.com/online-submission.php 